\title{
DEEP DRAWING FORMABILITY OF THE MEASUREMENT OF MAGNESIUM SHEET METALS
}

\author{
AKIHIRO MINAMI ${ }^{1}$, HIDETOSHI SAKAMOTO ${ }^{2}$ \& YASUO MARUMO $^{3}$ \\ ${ }^{1}$ Ariake National College of Technology, Japan \\ ${ }^{2}$ Doshisha University, Japan \\ ${ }^{3}$ Kumamoto University, Japan
}

\begin{abstract}
In the field of sheet metals forming, the press forming is executed as important method for mass production processing. It is reported that the plastic formability of Mg-alloy improves in the warm working. The warm deep drawing tests was carried out by using the 2 kinds of punch diameter, $30 \mathrm{~mm}$ and $50 \mathrm{~mm}$. This paper describes about the optimum deep drawing conditions with forming temperature and lubricant in the magnesium AZ31B alloy and the flame retardant magnesium alloy AMX602. These $\mathrm{Mg}$ alloys are difficult to mold at room temperature. However, in forming temperature at $180^{\circ} \mathrm{C}-200^{\circ} \mathrm{C}$, Limiting Drawing Ratio (LDR) of AZ31B became 2.65. The optimum forming temperature condition of AZ31B is $180^{\circ} \mathrm{C}-200^{\circ} \mathrm{C}$. The value of LDR decreases at $200^{\circ} \mathrm{C}$ or more. LDR of retardant magnesium alloy AMX602 is also 2.65 at the temperature at $300^{\circ} \mathrm{C}-320^{\circ} \mathrm{C}$. The optimum temperature conditions of retardant magnesium alloy AMX602 is assumed to be $300^{\circ} \mathrm{C}$ or more. After molding, the thickness decreases from the punch shoulder to the part around the sidewall. The magnesium alloys in thickness change is similar to the common deep drawing with the other materials. In AZ31B alloy and AMX602 alloy, the failure pattern is often occurred at sidewall area and punch-shoulder area respectively.

Keywords: deep drawing, magnesium, formability, limiting drawing ratio.
\end{abstract}

\section{INTRODUCTION}

Magnesium (Mg) has the smallest density in metallic structure materials and this material is an attractive material from the point of lightening the various machines and machine elements. Mg has the following advantages: (1) High specific tensile strength (tensile strength/density) and high rigidity, (2) Good shield effect for electromagnetic radiation, high absorption of vibration and impact load, (3) Small secular distortion, etc. [1]. In addition, it is good material in the recyclability as well as the nonferrous metals such as aluminum. Resource and energy conservation can be achieved by using these characteristics, and the solution of global environmental concerns can be borne fairly.

Recently, Mg alloys are used variously for the equipment related to electronic equipment cases such as the parts of automobile and the aircraft, the laptop computers and the mobile phones, the bicycle parts, the sport goods, the medical equipment, and so on. Many of these products are made from the die-cast method or the thixomolding method. Mg alloy is a close-packed hexagonal lattice structure, so the plastic forming at room temperature is difficult shown in Fig. 1 [2], [3], but the press forming in simple shape is comparatively applied. It is also known that the deep drawing of Mg alloys are remarkably improved under warm forming. For high quality and cost reduction of Mg products, a plastic forming method capable of high-precision mass production is desirable, and its technical development has been tried in many fields.

In this study, the forming conditions (temperature, lubrication condition, forming condition) were changed, the deep drawing test was carried out. These influences on forming was examined, and the best deep drawing condition of the Mg alloy was derived. 


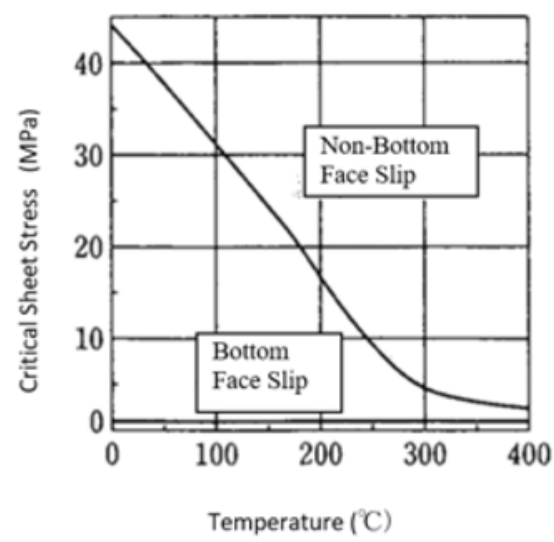

Figure 1: The temperature dependency of the critical shear stress of base slip and non-base slip.

\section{EXPERIMENTAL CONDITIONS}

The material used by this study is Mg alloy (AZ31B and AMX602). In this study, the $1 \mathrm{~mm}$ thickness circular blank sheet specimen of AZ31B and the flame retardant magnesium alloy AMX602 were used. Blank material specimens are cut out by $\mathrm{CO}_{2}$ laser machine. The laser machine processing condition is indicated in Table 1.

The universal forming machine used for an experiment is indicated in Fig. 2. The maximum punch load of this equipment is $784 \mathrm{kN}$ (80Tonf), and the maximum blank holder load is $490 \mathrm{kN}$ (50Tonf). Blank heating equipment is shown in Fig. 3. The temperature is controlled by using thermal regulator and a solid relay.

As the deep drawing tests are carried out under elevated temperature conditions, two heaters of the ratings $110 \mathrm{~V}, 2000 \mathrm{~W}$ and the ratings $100 \mathrm{~V}, 650 \mathrm{~W}$ are set on the die side and two heaters of ratings $110 \mathrm{~V}, 700 \mathrm{~W}$ are set on the suppression side for wrinkles. The insulator (mug wool) was wrapped around surroundings of each heater. The sheet insulation slab was set on respectively between the pressure dome and the table, and between the blank holder and the substance.

In deep drawing, the punch (punch shoulder radius $\mathrm{r}_{\mathrm{p}}=8 \mathrm{~mm}$ ), the die (die shoulder radius $r_{d}=8 \mathrm{~mm}$ ) and the blank holder (blank holder shoulder radius $r_{s}=8 \mathrm{~mm}$ ) were used for the punch diameter $D_{p}=50 \mathrm{~mm}$. In the case of the punch diameter $D_{p}=30 \mathrm{~mm}$, the punch (punch shoulder radius $r_{p}=48 \mathrm{~mm}$ ), the die (die shoulder radius $r_{d}=48 \mathrm{~mm}$ ) and the blank holder (blank holder shoulder radius $\mathrm{r}_{\mathrm{s}}=4 \mathrm{~mm}$ ) were used. The punch speed is about $1.4 \mathrm{~mm} / \mathrm{sec}$. In the punch diameter $\varphi 50$, the $A Z 31 \mathrm{~B}$ deep drawing tests were carried out at $\mathrm{T}_{\mathrm{B}}=\mathrm{room}$ temperature, $80^{\circ} \mathrm{C}, 160^{\circ} \mathrm{C}, 180^{\circ} \mathrm{C}, 200^{\circ} \mathrm{C}, 220^{\circ} \mathrm{C}$ and $250^{\circ} \mathrm{C}$. In the punch diameter $\varphi 30$, the test was carried out at $\mathrm{T}_{\mathrm{B}}=190^{\circ} \mathrm{C}-200^{\circ} \mathrm{C}$. In case of flame retardant magnesium $\mathrm{Mg}$ alloy AMX602, the drawing tests are carried out at $\mathrm{T}_{\mathrm{B}}=$ room temperature, $80^{\circ} \mathrm{C}, 200^{\circ} \mathrm{C}, 260^{\circ} \mathrm{C}$, $280^{\circ} \mathrm{C}, 300^{\circ} \mathrm{C}$ for the punch diameter $\varphi 50$, and $290^{\circ} \mathrm{C}, 300^{\circ} \mathrm{C}, 310^{\circ} \mathrm{C}, 320^{\circ} \mathrm{C}$ for the punch diameter $\varphi 30$, respectively.

The lubrication conditions of the AZ31B are the hydraulic counter pressure and the polyethylene sheet (P.E.) at room temperature. In the case of worm working, the two kinds 
Table 1: Laser working conditions.

\begin{tabular}{|c|c|}
\hline \multicolumn{2}{|c|}{} \\
Material: $\mathrm{Mg}$ ( AZ31B, AMX602) \\
\hline Blank thickness (mm) & 1.0 \\
\hline Assist gas & Air \\
\hline Oscillation condition & Pulse \\
\hline Laser output (W) & 1000 \\
\hline Frequency (Hz) & 500 \\
\hline Duty ratio (\%) & 70 \\
\hline Feed velocity (mm/min) & 1600 \\
\hline
\end{tabular}

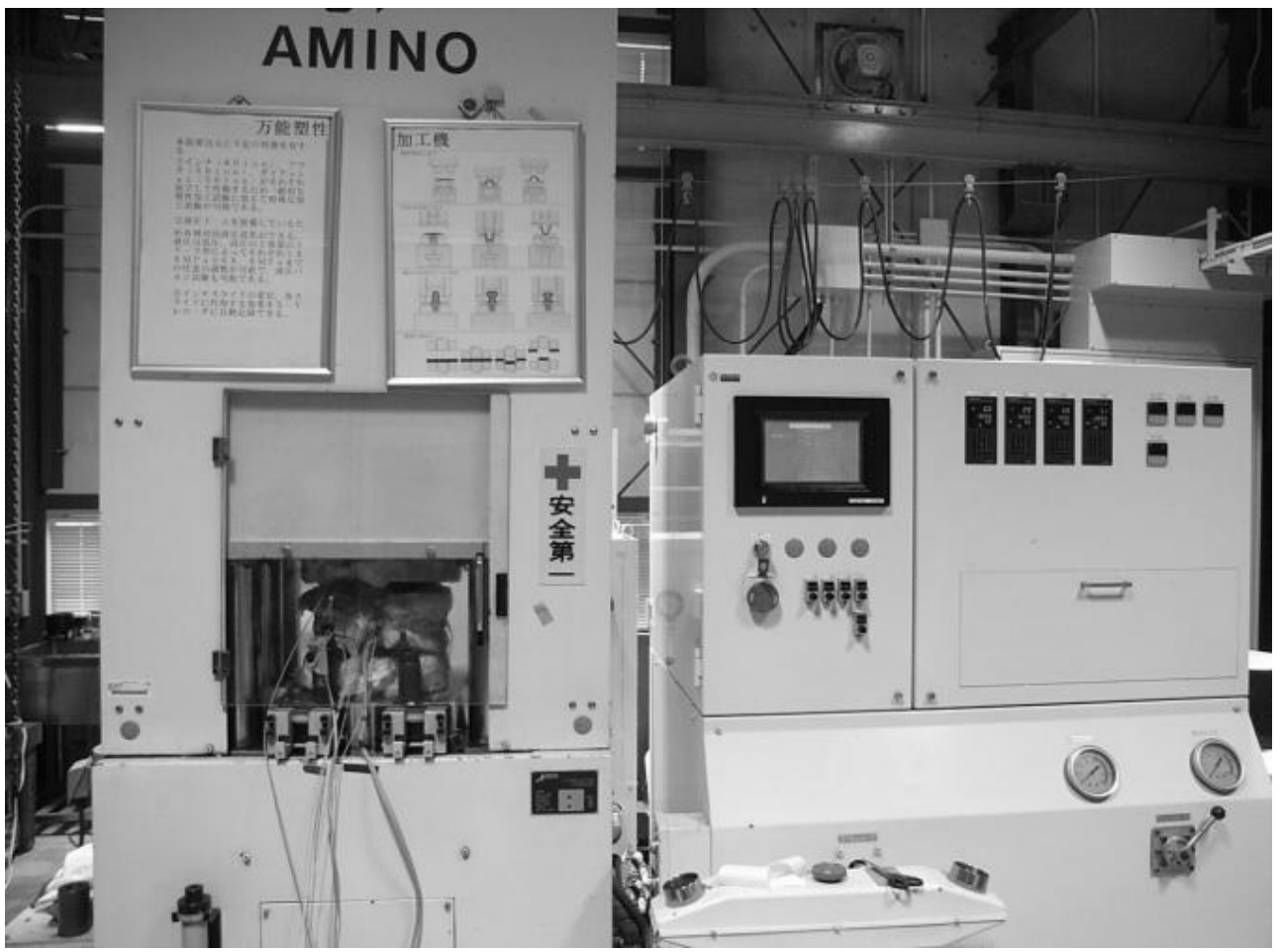

Figure 2: Universal forming machine.

of lubricant were used. One is the lubricant which dissolved a powder of fluoroplastic (PTFE) in oil, and others is the combination of the PTFE sheet and the press metal working lubricant. The lubrication condition of AMX602 is PTFE seat +GM-100 (magnesium exclusive lubricant (NIHON KOUSAKUYU: Japanese metal working lubricant Corporation)). 


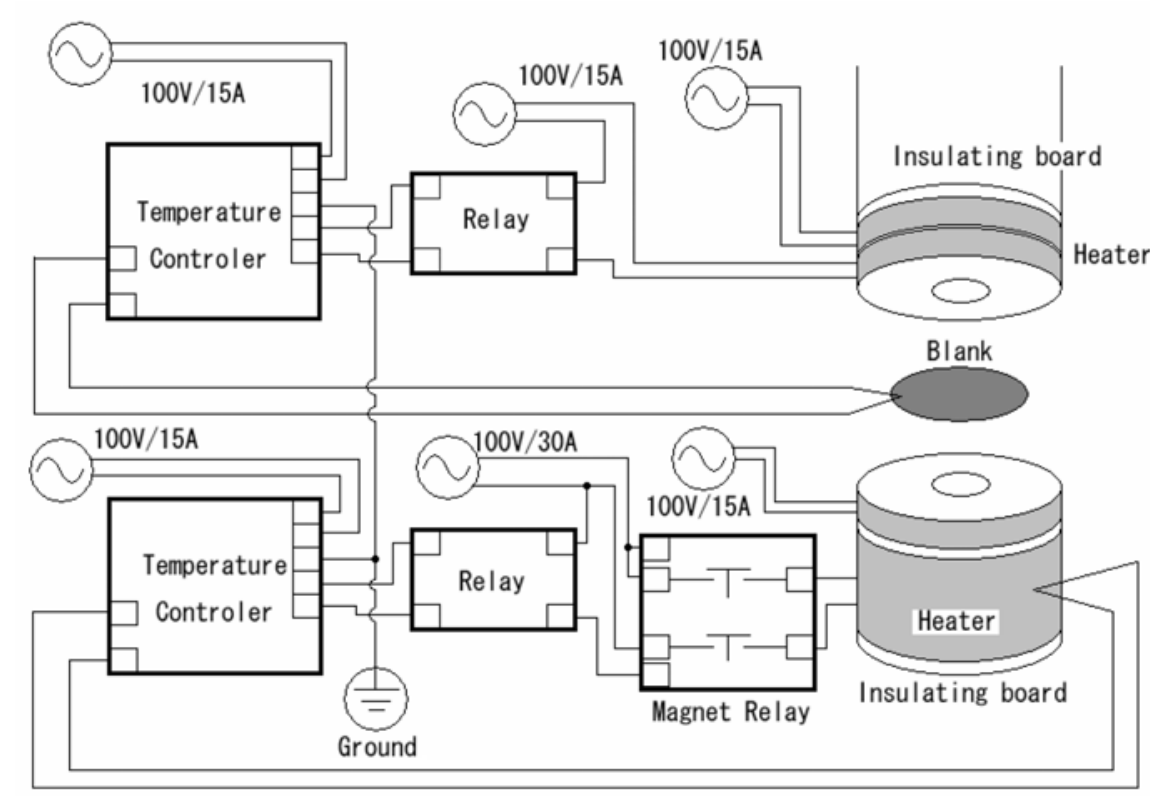

Figure 3: Schematic diagram of the heating device.

\section{DEEP DRAWING TEST}

Limiting Drawing Ratio LDR $\left(\mathrm{LDR}=\mathrm{D}_{\mathrm{B}_{\max }} / \mathrm{D}_{\mathrm{p}}\right)$ is used as form-ability index. Here, $\mathrm{D}_{\mathrm{p}}$ is a punch diameter, $\mathrm{D}_{\mathrm{B}}$ is a blank diameter, and $\mathrm{D}_{\mathrm{Bmax}}$ is the maximum blank diameter at the deep drawing success.

\subsection{Deep drawing result of AZ31B (rolling material)}

\subsubsection{The case of $\phi 50$ punch}

In $\mathrm{T}_{\mathrm{B}}=80^{\circ} \mathrm{C}$, the $\phi 70$ minimum blank specimen broke under $\mathrm{LDR}=1.4$. Heating to $\mathrm{T}_{\mathrm{B}}$ $=160^{\circ} \mathrm{C}$, the forming have improved to LDR up to 2.5 . In $180^{\circ} \mathrm{C}-200^{\circ} \mathrm{C}$, the maximum value $\mathrm{LDR}=2.6$ was obtained.

When the forming temperature $\mathrm{T}_{\mathrm{B}}$ is raised to $220^{\circ} \mathrm{C}$ and $250^{\circ} \mathrm{C}$, LDR has gradually decreased to 2.4 and 2.3 .

Because the critical shearing stress in slipping surface respects other than the bottom slipping surface of the crystal lattice structure is large at $80^{\circ} \mathrm{C}$, the plastic deformation become difficulty at this temperature. By elevating temperature up to $160^{\circ} \mathrm{C}$, LDR is improved because the critical shearing stresses of slipping in respects other than the bottom drop to a lower value.

The value of LDR is gradually decreasing from the peak at $T_{B}=200^{\circ} \mathrm{C}$. Ductility rises with the temperature rise. However, LDR drop to a lower value because it is easy to break by reducing the strength. Fig. 4 shows the forming success example of $D_{B}=125 \mathrm{~mm}$ and $\mathrm{T}_{\mathrm{B}}=160^{\circ} \mathrm{C}$.

The failure pattern is a wrinkle and a crack by buckling at $\mathrm{T}_{\mathrm{B}}=80^{\circ} \mathrm{C}$. It is thought that such a crack was caused because the critical shearing stresses of slipping in respects other than the bottom are high and the ductility is low. The starting point of the crack is at the punch 
shoulder and the sidewall crack around punch shoulder at $\mathrm{T}_{\mathrm{B}}=160^{\circ} \mathrm{C}-250^{\circ} \mathrm{C}$. Fig. 5 shows the failure example in $\mathrm{D}_{\mathrm{B}}=130 \mathrm{~mm}$ and $\mathrm{T}_{\mathrm{B}}=160^{\circ} \mathrm{C}$.

The lubrication performance was compared between the lubricant of the PTFE sheet together with the press construction oil and the lubricant of PTFE solution.

The PTFE sheet has decreased the punch load to about 30\% compared with the PTFE solution shown in Fig. 6. It is thought that the steady lubrication effect was achieved because the PTFE sheet covers the contact region and the lubrication performance has improved.

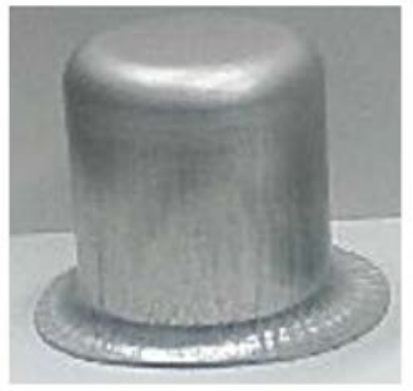

Figure 4: Forming success example (DBmax=125mm, $\mathrm{LDR}=2.5)$.

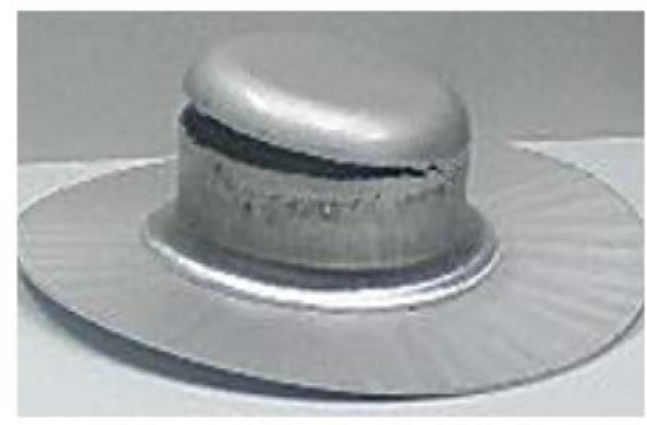

Figure 5: Broken example $\left(\mathrm{D}_{\mathrm{B}}=130 \mathrm{~mm}\right)$.

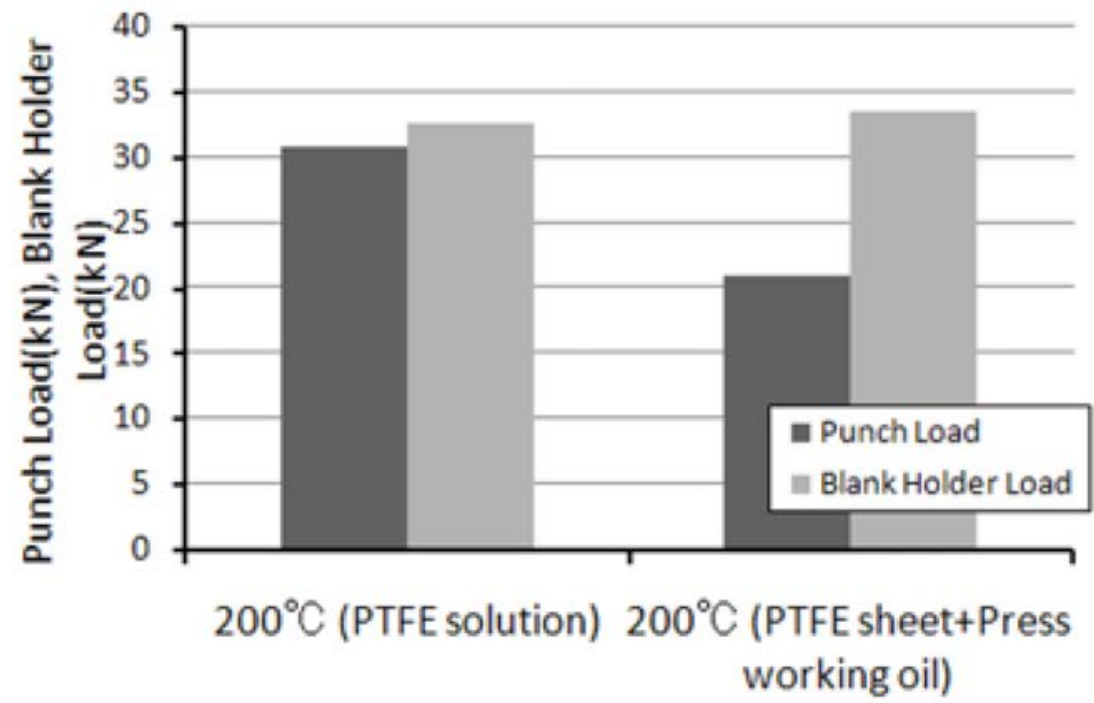

Figure 6: Relationship between lubricants and punch load, blank holder load. 


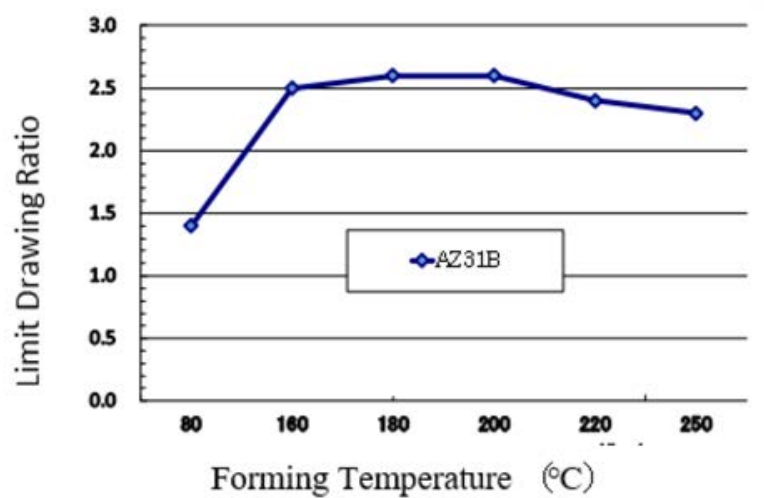

Figure 7: Relationship between forming temperature and LDR in AZ31B and LDR in AZ31B.

3.1.2 The case of $\phi 30$ punch

In $\mathrm{TB}=190^{\circ} \mathrm{C}-200^{\circ} \mathrm{C}$ and PTFE sheet $+\mathrm{GM}-100$ lubricant, $\mathrm{LDR}=2.65$ was able to be achieved. The DDH (Drawing depth height) was about $41-42 \mathrm{~mm}$ at $\mathrm{DR}=2.6$. The DDH at $\mathrm{LDR}=2.65$ was about $38 \mathrm{~mm}-39 \mathrm{~mm}$ and the forming success rate are $33 \%$. The failure pattern is mainly the die shoulder crack at $\mathrm{T}_{\mathrm{B}}=320^{\circ} \mathrm{C}$.

\subsection{Deep drawing result of AMX602}

\subsubsection{The case of $\phi 50$ punch}

The flame retardant $\mathrm{Mg}$ alloy used the extrusion material at the normal temperature, $80^{\circ} \mathrm{C}$, $200^{\circ} \mathrm{C}, 260^{\circ} \mathrm{C}, 280^{\circ} \mathrm{C}$ and $300^{\circ} \mathrm{C}$.

In flame retardant $\mathrm{Mg}$ alloy, giving the counter hydraulic pressure, the value of $\mathrm{LDR}=1.4$ is obtained at room temperature. In the case of no counter hydraulic pressure, the plate specimen broke at less than $\mathrm{LDH}=1.4$ at room temperature, but $\mathrm{LDR}=1.4$ was achieved at $80^{\circ} \mathrm{C}$. At the $200^{\circ} \mathrm{C}, \mathrm{LDR}=1.6$ was obtained. Elevating temperature, the form-ability of flame retardant $\mathrm{Mg}$ alloy was slightly improved, but the ratio of the improvement is considerably lower than that of AZ31B. However, $\mathrm{LDR}=2.2$ and $\mathrm{LDR}=2.5$ were obtained at $260^{\circ} \mathrm{C}$ and at $280^{\circ} \mathrm{C}-300^{\circ} \mathrm{C}$, respectively. This shows that higher temperatures than AZ31B are necessary in the forming of flame resisting magnesium. The reason is that the temperature rise decreases the critical shearing stress of the plastic deformation of the flame retardant $\mathrm{Mg}$ alloy.

The failure pattern is a crack along the line in the direction of the extrusion from the room temperature to $200^{\circ} \mathrm{C}$. This failure pattern depends on the poor ductility at the room temperature, and the surface roughness under forming process. The crack was caused from the punch shoulder crack and the sidewall crack at $260^{\circ} \mathrm{C}-300^{\circ} \mathrm{C}$. The forming success example of AMX602 is shown in Fig. 8 and the failure example is shown in Fig. 9 at $260^{\circ} \mathrm{C}$, respectively. 


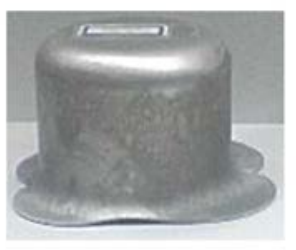

Figure 8: Forming success example $\left(\mathrm{D}_{\mathrm{B}}=110 \mathrm{~mm}\right.$, $\mathrm{LDR}=2.2)$.

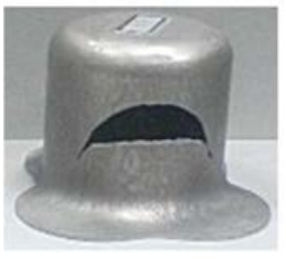

Figure 9: Failure example $\left(\mathrm{D}_{\mathrm{B}}=115 \mathrm{~mm}\right)$.

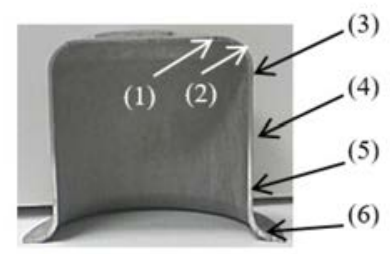

Figure 10: Section of forming metal.

Table 2: Thickness of after forming (mm).

\begin{tabular}{|l|l|}
\hline$(1)$ & 0.975 \\
\hline$(2)$ & 0.915 \\
\hline$(3)$ & 0.822 \\
\hline$(4)$ & 0.946 \\
\hline$(5)$ & 1.015 \\
\hline$(6)$ & 1.358 \\
\hline
\end{tabular}

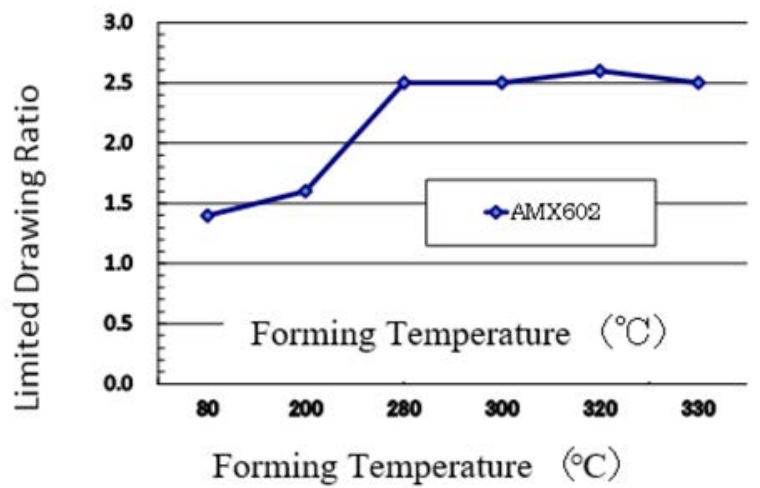

Figure 11: Relationship between forming temperature and LDR in retardant magnesium.

The measuring result of the thickness of AMX602 of blank diameter $\phi 125$ at the forming temperature $260^{\circ} \mathrm{C}$ is shown in Table 2 and the measurement points are shown in Fig. 10, respectively. The thicknesses of sidewall from the punch shoulder to the vicinity of the punch shoulders became thin. This thickness distribution arises from the distribution of large pressure around the punch shoulder. Therefore, initial crack caused from the punch shoulder and the sidewall vicinity of punch shoulder. This plate thickness distribution has similar trend to deep drawing such as the stainless steel and titanium. The thickness decrease of $18 \%$ was observed at area (2) and the thickness increase of 35\% was observed at the area (6). 
8 Computational Methods and Experimental Measurements XVIII

\subsubsection{The case of $\phi 30$ punch}

LDR 2.65 was obtained at the range of forming temperature $\mathrm{T}_{\mathrm{B}}=290^{\circ} \mathrm{C}-300^{\circ} \mathrm{C}$. Here, the combination lubricant PTFE sheet + GM-100 was used. The failure pattern was mainly die shoulder crack. The sidewall crack was also recognized at the forming temperature $\mathrm{T}_{\mathrm{B}}=350^{\circ} \mathrm{C}$. The forming example and the failure example are shown in Fig. 12 and Fig. 13, respectively.

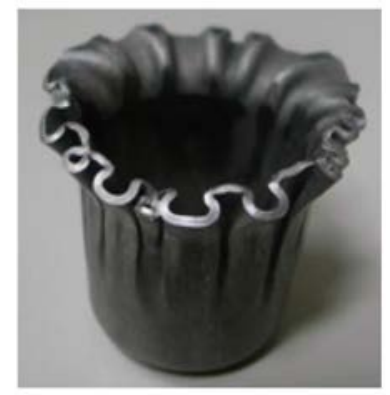

Figure 12: Forming example $\left(\mathrm{D}_{\mathrm{B}}=79.5, \mathrm{LDR}=2.65\right)$.

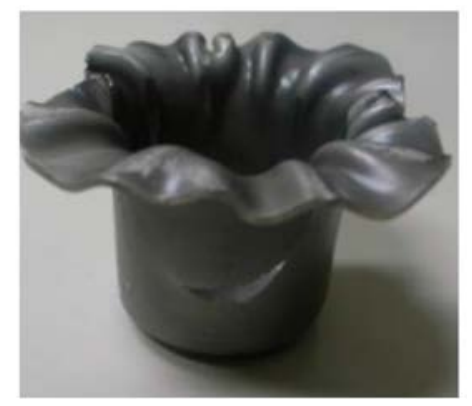

Figure 13: Failure example $\left(\mathrm{D}_{\mathrm{B}}=81.0 \mathrm{~mm}, \mathrm{DR}=2.70\right)$.

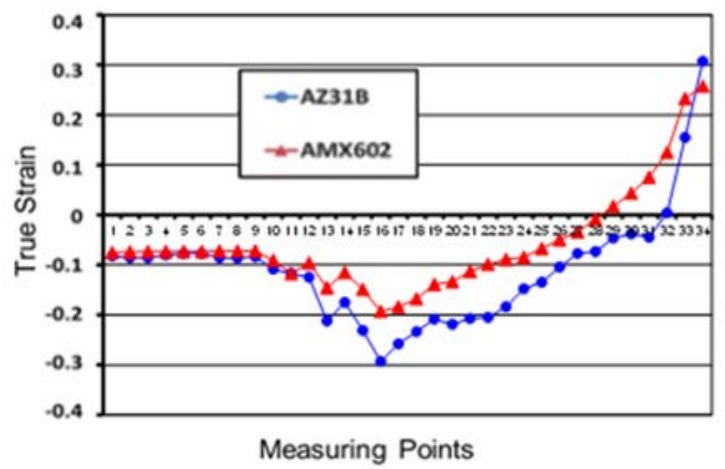

Figure 14: True strain distribution $\left(\mathrm{P}_{\mathrm{D}}=50 \mathrm{~mm}\right)$. 
3.3 Plate thickness change after molding (AZ31B \& AMX602)

\subsubsection{The case of $\phi 50$ punch}

The true strain distribution of AZ31B and AMX602 are shown in Fig. 14 respectively. Both material's true strain distributions show a similar tendency. However, the thicknessdecreasing ratio of AZ31B is larger than that of AMX602.

\subsubsection{The case of $\phi 30$ punch}

In the case of $\phi 30$ punch, it is tendency that the wrinkle is generated in the one side and the opposite side is without the wrinkle of the deep drawing. The LDR values of AMX602 and AZ31B are both 2.65. These true strain distributions are shown in Fig. 15 and Fig. 16, respectively.

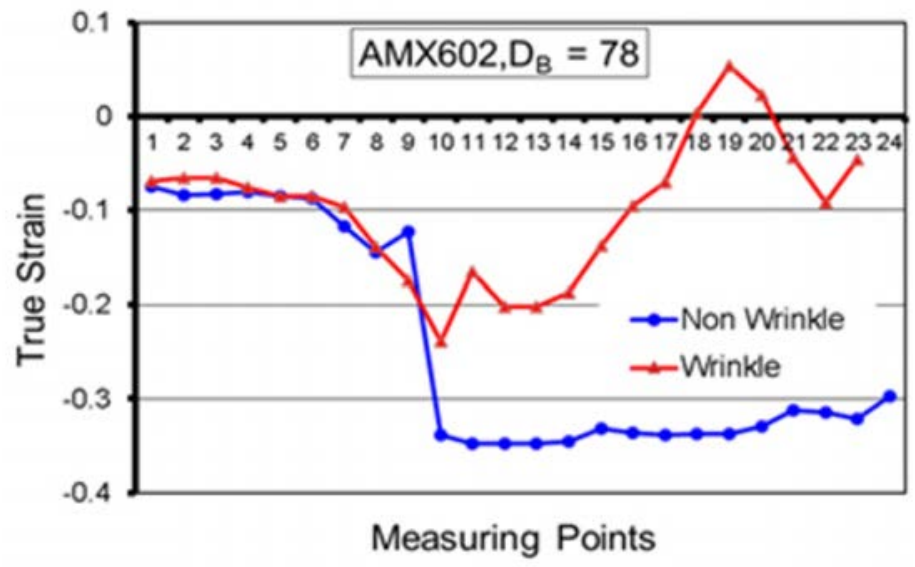

Figure 15: True strain distribution $\left(\mathrm{P}_{\mathrm{D}}=30 \mathrm{~mm}\right)$.

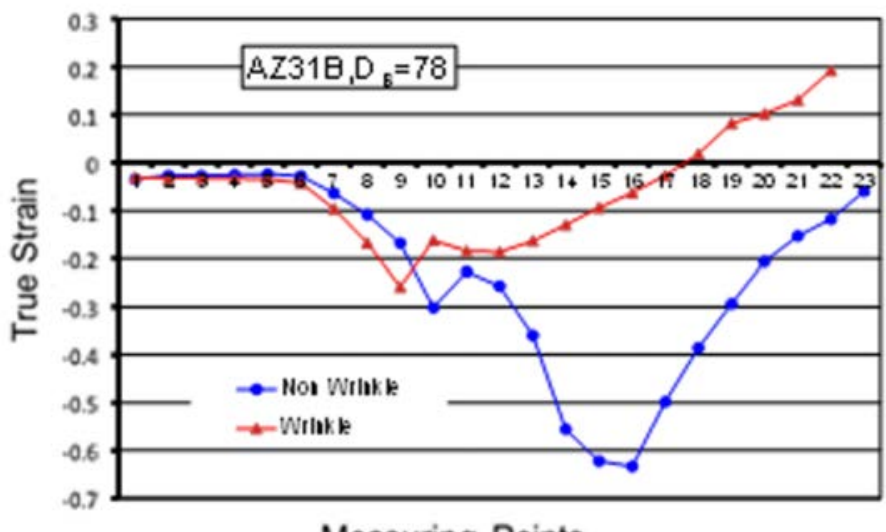

Measuring Points

Figure 16: True strain distribution $\left(\mathrm{P}_{\mathrm{D}}=30 \mathrm{~mm}\right)$. 


\section{CONCLUSIONS}

1. AZ31B showed the best form-ability at the temperature region from $180^{\circ} \mathrm{C}$ to $200^{\circ} \mathrm{C}$, and $\mathrm{LDR}=2.6$ for punch diameter $50 \mathrm{~mm}$, and $\mathrm{LDR}=2.65$ or punch diameter $30 \mathrm{~mm}$ were obtained, respectively.

2. AMX602 showed the best form-ability at the temperature region from $280^{\circ} \mathrm{C}$ to $300^{\circ} \mathrm{C}$, and $\mathrm{LDR}=2.5$ for punch diameter $50 \mathrm{~mm}$, and $\mathrm{LDR}=2.65$ for punch diameter $30 \mathrm{~mm}$ were obtained, respectively.

3. The temperature regions of best form-ability were $180^{\circ} \mathrm{C}-200^{\circ} \mathrm{C}$ for $\mathrm{AZ31B}$, and $280^{\circ} \mathrm{C}-$ $300^{\circ} \mathrm{C}$ for AMX602.

4. The larger LDR was obtained in the punch diameter $30 \mathrm{~mm}$ of AZ31B and AMX602.

\section{REFERENCES}

[1] The Japan Society for Technology of Plasticity, Magnesium Processing Technology, pp. 11-30, 2009.

[2] Yoshinaga, H., Metallic Physics, 10, p. 91, 1963.

[3] Yoshinaga, H. \& Horiuchi, R., Trans. JIM, 4, p. 1, 1963. 